\title{
Analysis and NN-Based Control of Doubly Fed Induction Generator in Wind Power Generation
}

\author{
Orlando Manuel Soares ${ }^{1}$, Henrique Nuno Gonçalves ${ }^{2}$, António Pina Martins ${ }^{2}$ and Adriano Silva Carvalho ${ }^{2}$ \\ ${ }^{1}$ Escola Superior de Tecnologia e de Gestão \\ Instituto Politécnico de Bragança \\ Campus de Santa Apolónia, 5301-857 Bragança, Portugal \\ E-mail: osoares@ipb.pt \\ ${ }^{2}$ Faculdade de Engenharia da Universidade do Porto \\ Rua Dr. Roberto Frias, 4200-465 Porto, Portugal \\ E-mail: henrique@fe.up.pt, ajm@fe.up.pt and asc@fe.up.pt
}

\section{Keywords}

Wind power generation, Simulation, Control, Neural networks, Doubly fed induction generator.

\section{The DFIG Control Structure}

This paper deals with two control techniques for the Doubly Fed Induction Generator connected to a wind turbine: PI controllers and neural networks based controllers. The adopted induction generator model is the qd0 stationary rotating reference frame model and a back-to-back PWM converter is used, [1]-[2].

The aim of the rotor-side converter is the independent control of the active power and reactive power. The aim of the grid-side converter is to keep constant the DC voltage in the intermediate capacitor in order to guarantee an operation of the converter with unity power factor guaranteeing only the exchange of reactive power through the stator, [3]. The grid-side converter control diagram is shown in Figure 1.

The control of the induction generator rotor is carried through in a synchronous rotating dq referential, with the $\mathrm{d}$-axis aligned with the stator flux position. In this way decoupling between the electromagnetic torque and the rotor magnetizing current can be obtained, as shown in Figure 2. The new control system uses a NN to substitute some blocks of the traditional vector control system, [4].

\section{Comparative Results}

It is intended to verify the system response due to a variation of the active power flow, obtained through a variation in the quadrature component of the rotor current. This variation consisted in applying a negative pulse of amplitude equal to 0,2 p.u. The reference voltage signals for the controller of the rotor-side converter have been registered in Figure 3 and the power flows in Figure 4 (NN in the blue colour and PI in green colour).

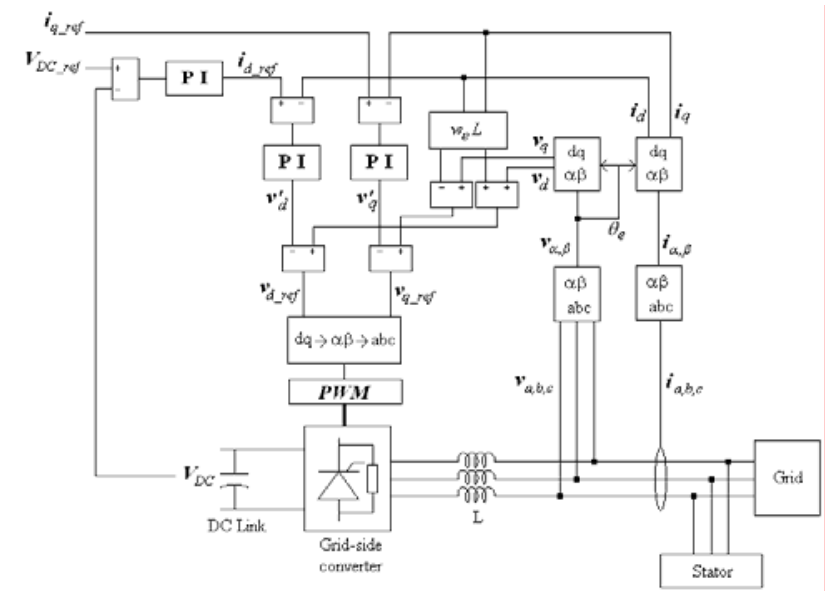

Fig. 1. Grid-side converter controller diagram.

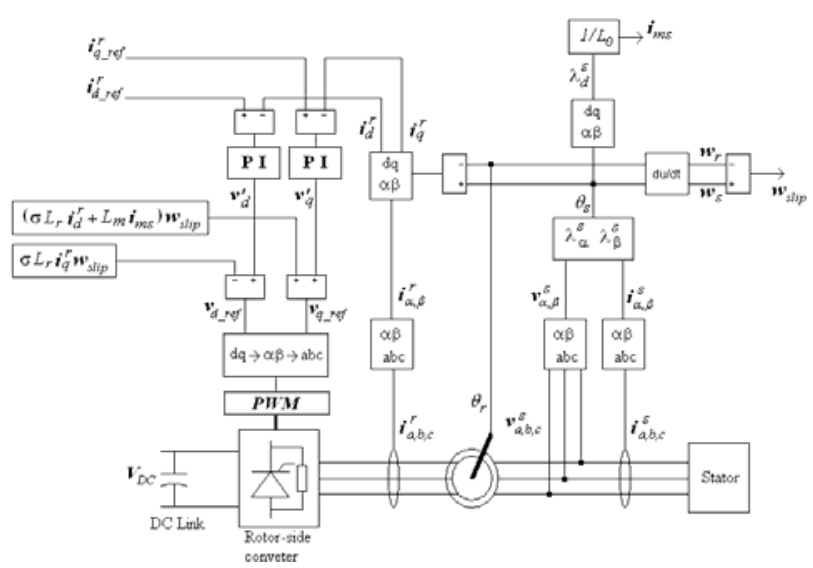

Fig. 2. Rotor-side converter controller diagram.

The maximum difference verified between the two control types is less than $0.5 \%$. The NNs present, generally, transients of lesser amplitude and greater speed to reach the steady-state condition. This behaviour is also verified in the main electric and mechanical variables. 

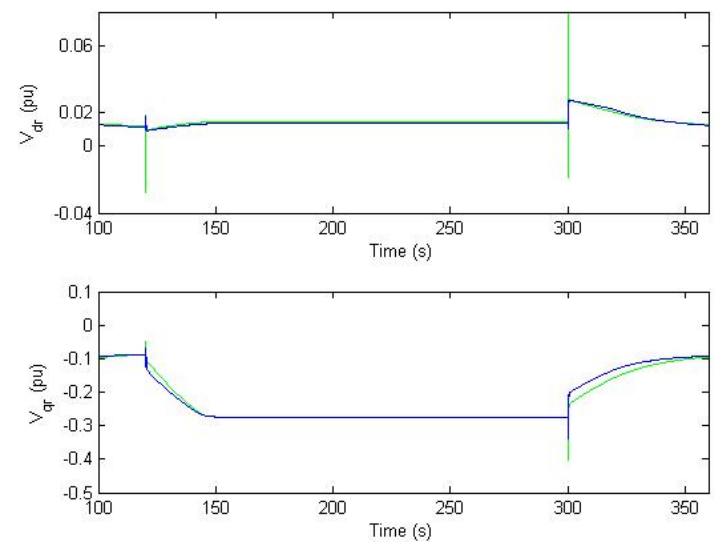

Fig. 3. Reference rotor-side voltage $v_{d q}$, due to active power control.
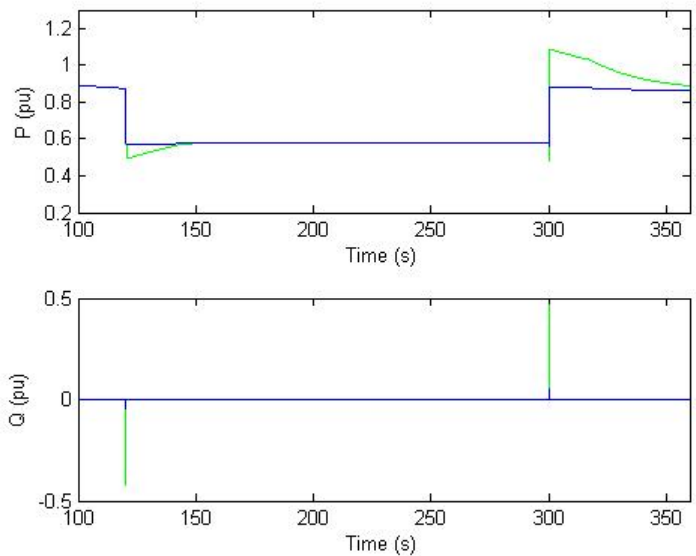

Fig. 4. Active power and reactive power, due to active power control.

A phase-to-earth fault in a line of the electrical network located near the wind park occurred at $t=180 \mathrm{~s}$ with a duration of $180 \mathrm{~ms}$. The fault impedance was $1 \mathrm{~m} \Omega$. Figures 5 and 6 show the signals of the reference voltages used to control the stator-side and the rotor-side converters, with NNs (in the blue colour) and PIs (in the green colour).
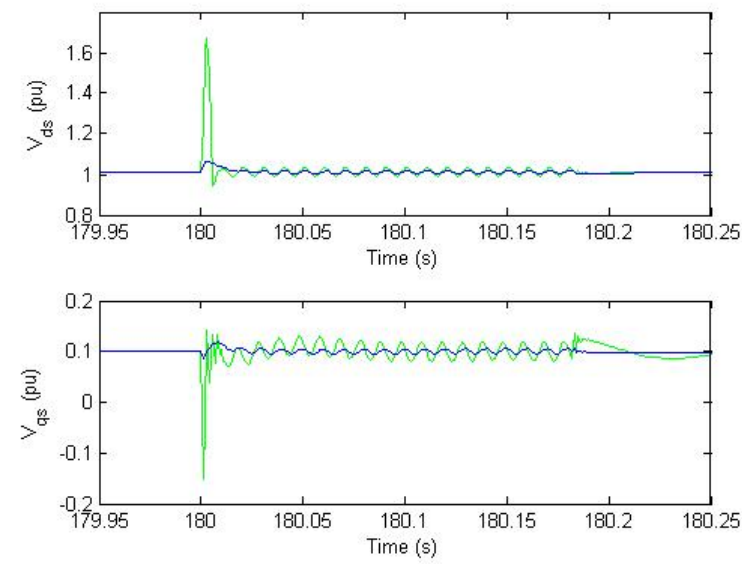

Fig. 5. Reference grid-side voltage $v_{d q}$, due to a phase-to-earth fault.

During the fault period, it was verified that the NNs response presents better results than the system using PI controllers; beside the peaks already related previously in the transitions, they present a lesser ripple. It is important to relate that in the direct component of the stator voltage with PI controllers the peaks can reach about 1,7 p.u. and that can cause some unwanted effects in the electronic devices used in the converters.
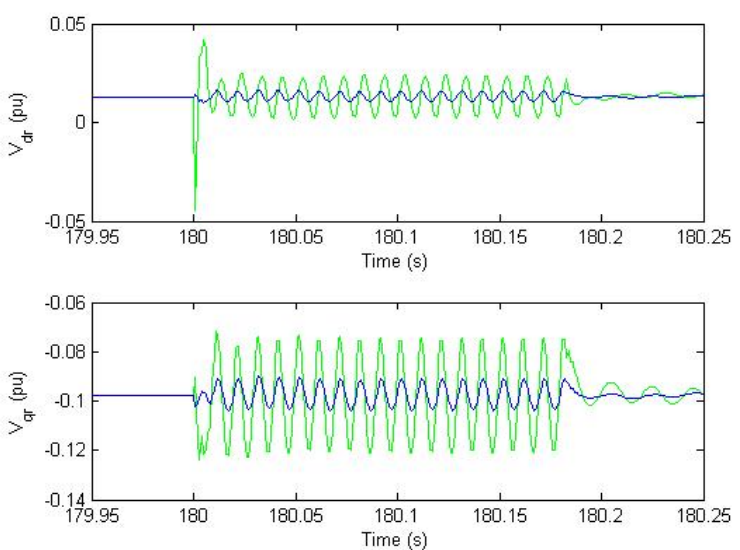

Fig. 6. Reference rotor-side voltage $v_{d q}$, due to a phase-to-earth fault.

The disturbances caused in the active power and reactive power delivered to the grid are smoother with the use of the NNs.

\section{Conclusion}

The NN-based system that estimates the control parameters of the generator shown good characteristics, as was verified in the presented results. Some differences in the controllers responses using neural networks can be noticed, namely three positive and advantageous aspects: transient regimes present smaller overshoots, or absence of them in some cases, what corresponds to less severe transitions; a faster response, i.e. the system retakes the permanent regimen in lesser time; and smaller oscillatory behaviour.

It was demonstrated that the reference signals for the grid-side and rotor-side converters of the DFIG can be obtained using control systems based in NNs. These can substitute most of the blocks of a conventional control system, and with the referred advantages.

\section{References}

[1] A. Tapia, G. Tapia, J. X. Ostolaza, J. R. Saenz, R. Criado, J. L. Berasategui, "Reactive power control of a wind farm made up with doubly fed induction generators", (I) and (II), IEEE Porto Power Tech Conference, 2001.

[2] R. Pena, J. C. Clare, G. M. Asher, "Doubly fed induction generator using back-to-back PWM converters and its application to variable-speed wind-energy generation”, IEE Proc.-Elect. Power Appl., vol. 143, no 3, May 1996.

[3] T. Ackermann, "Wind Power in Power Systems", John Wiley \& Sons, Ltd, England, 2005.

[4] M. G. Simões, B. K. Bose, "Neural network based estimation of feedback signals for vector controlled induction motor drives", IEEE Transactions on Industry Applications, vol. 31, no 3, pp. 620-629, May-June 1995. 